\title{
PROPOSTA DIDÁTICA COM ANIMAÇÃO DE CARTAS SINÓTICAS DE SUPERFÍCIE
}

\author{
DIDACTIC PROPOSAL WITH ANIMATION OF SURFACE \\ SYNOPTICS CHARTS \\ PROPUESTA DIDÁCTICA CON ANIMACIÓN DE CARTAS \\ SINÓPTICAS DE SUPERFICIE
}

Ercilia Torres Steinke

Departamento de Geografia, Universidade de Brasília;

erciliaunb@gmail.com

Valdir Adilson Steinke

Departamento de Geografia, Universidade de Brasília;

valdirsteinke@gmail.com

Luis Alberto Martins Palhares de Melo

Embrapa Recursos Genéticos e Biotecnologia;

palhares65@gmail.com

Resumo: A animação pode se traduzir num importante recurso didático para o ensino dos sistemas meteorológicos atuantes em um território. Neste artigo, além de descrever a elaboração de um software de animação de cartas sinóticas de superfície, apresenta-se uma proposta didática utilizando-se essa ferrame nta. Observou-se que a prática interferiu de forma positiva no aprendizado, funcionando como um recurso facilitador na compreensáo do ritmo da sucessão anual dos estados atmosféricos.

Palavras-chave: Ensino, Climatologia, Cartas Sinóticas

\begin{abstract}
The animation can be translated into an important didactic resource for the teaching of meteorological systems operating in a territory. In this article, besides describing the elaboration of an animation software of surface synoptic charts, a didactic proposal is presented using this tool. It was observed that the practice interfered positively in learning, functioning as a resource that facilitate the understanding of rhythm of the annual succession of atmospheric states.
\end{abstract}

Keywords: Teaching, Climatology, Synoptic Charts. 
Resumem: La animación se puede traducir en un importante recurso para la enseńanza de los sistemas meteorológicos que operan en un territorio. En este artículo, además de describir el desarrollo de un software de animación de cartas sinópticas de superficie, se presenta una propuesta didáctica utilizando esta herramienta. Se observó que la práctica interfirió positivamente en el aprendizaje, y sirvió como un recurso facilitador en la comprensión del ritmo de la sucesión anual de estados atmosféricos.

Palabras-clave: Enseñanza, Climatología, Carta Sinóptica

\section{INTRODUÇÃO}

Ensinar temas de Climatologia no escopo da Geografia, seja no Ensino Básico, seja no Ensino Superior, não constitui uma tarefa simples. Em primeiro lugar, porque trata-se de um conteúdo complexo, abstrato e permeado de conteúdos, ainda que básicos, de Física que, muitas vezes, os professores de Geografia não dominam (SANTOS e ROCHA, 2014). Pesquisas, tais como a de Steinke e Carvalho (2013) e Taveira e Steinke (2014) apontam para o fato de que, entre os temas de maior dificuldade para ensinar, juntamente com a Cartografia, encontram-se os da Geografia Física, incluindo aí a Climatologia. Steinke e Carvalho (2014) observaram que isso ocorre, entre outros fatores, em função do processo de formação universitária dos professores, que pode estar apresentando lacunas, em especial, nas temáticas consideradas das áreas técnica e física da Geografia. Essa constatação corrobora com o que Oliveira (2010) concluiu em sua pesquisa com professores da rede pública de Goiânia. A maioria dos professores entrevistados atribuiu a dificuldade de ensinar determinados assuntos da Geografia Física ao seu processo formativo na graduação.

A falta de preparo dos professores reflete no interesse dos alunos pela disciplina, em sala de aula. Várias pesquisas já mostraram que a disciplina de Geografia, de forma geral, constitui um fardo para os alunos, pois os mesmos náo são motivados a explorar os conteúdos de forma diferenciada, a não ser por meio da memorização. Silva (2011), por exemplo, realizou uma pesquisa onde propôs uma estratégia didática com a utilização de jogos, animaçóes e simuladores computadorizados para ministrar aulas de Geografia, para alunos do $8^{\circ}$ ano do Ensino Fundamental. Constatou que os alunos não se interessavam pelos conteúdos de Geografia por considerarem a disciplina muito enfadonha. Em conversa com os mesmos, a autora observou:

[...] eles tinham antipatia pela disciplina, definindo-a como desnecessária, chata, decoreba devido ser considerada enciclopédica a partir dessa observação resoluto que não devemos explicar apenas o que está escrito no livro e pronto, mas tentar mostrar pros alunos a importância da Geografia pro seu cotidiano, e apontar o quanto é interessante e divertido estudá-la. (SILVA, 2011, p. 5)

Já Brito e Ferreira (2012), tratando especificamente dos conteúdos de Climatologia escolar, afirmam que, justamente por ser um ensino tradicionalmente conteudista, que privilegia a memorização, com pouca, e às vezes, nenhuma articulação com a realidade vivida pelos estudantes, esses pouco se interessam em desvendar o porquê dos 
fenômenos que estudam na Climatologia. Quando se trata de atividades de fixação do conteúdo, aos alunos são oferecidas tarefas que estimulam muito mais a memorização do que outra capacidade cognitiva.

Acredita-se que, quando se aprende algo sem saber por que se está aprendendo, tanto na escola, quanto na universidade, costuma-se atribuir esse porquê ao fato de ser a disciplina uma obrigação acadêmica, o que se torna, muitas vezes, apenas algo mais para ser memorizado momentaneamente e depois esquecido. Contudo, quando aquilo que se aprende é articulado com a realidade, com os fatos do cotidiano do aluno, o interesse no assunto cresce e, conforme bem ressalta Costella (2007, p. 50), ao substituir esquemas já construídos por reflexões e novas construçóes de conceitos nós somos incentivados a desenvolver um pensamento autônomo que desperta o desafio e a satisfaçáo do saber que vem da construção.

Steinke (2012, p. 13) concorda com essa afirmação e a respeito dos conteúdos de Climatologia faz a seguinte consideração:

Imagine, por exemplo, o modelo esquemático da circulação geral da
atmosfera, assunto que demanda bastante abstração por parte de um
estudante. Decorar nome, posiçáo dos centros de pressão atmosférica, células
de circulaçáo e ventos planetários pode náo ser tão difícil, mas certamente,
algum tempo depois não nos lembraremos mais desses nomes. Ao contrário,
se compreendermos a gênese e as características da circulação geral e a sua
relaçáo com a diferenciaçáo das paisagens no planeta Terra, o que é concreto
e faz parte da realidade, a probabilidade de náo nos esquecermos do esquema
é maior (STEINKE, 2012, p. 13).

Corroborando com as assertivas anteriores, Fialho (2013) retoma antigas preocupaçóes com relação ao ensino da Climatologia. Relata que tem observado que os alunos recém ingressados no curso de graduação em Geografia, na Universidade Federal de Viçosa (UFV), quando cursam a disciplina de Climatologia, apresentam uma defasagem de aprendizagem, não conseguem acompanhar o ritmo da aula e possuem dificuldade de compreensão de leituras obrigatórias. Segundo o autor, esses fatos podem estar atribuídos ao que os alunos aprenderam, ou deixaram de aprender, no ensino básico. Dessa forma, o autor insiste na seguinte pergunta: o ensino do clima hoje é interessante para o aluno? Possivelmente a resposta ainda seja não, tanto no ensino básico, quanto no superior. Enquanto o ensino náo deixar de ser enciclopédico e desarticulado, a resposta continuará sendo não.

Brito e Ferreira (2012) concordam que a abordagem dos conteúdos de Climatologia no Ensino Básico e porque náo, no superior, ainda se mostra muito tradicional. Os professores tratam os elementos climáticos de forma estática e aplicam exemplos distantes da realidade dos alunos. Estáo perdendo a oportunidade de mostrar para os seus alunos que a repercussão dos fenômenos atmosféricos na superfície terrestre se dá em um território, transformado e produzido pelo homem, de maneira desigual e apropriado segundo os interesses de agentes sociais - atribuição da análise geográfica do clima, o que se conhece por Climatologia Geográfica. 
Em pesquisa realizada sobre as noçóes de Climatologia na construçáo do conhecimento da Ciência Geográfica, no ensino Médio, Silva e Silva (2014) apontam:

O ensino da Climatologia Geográfica na maioria das escolas não adere à aplicabilidade de atividades lúdicas, nem da contextualização do conteúdo expresso no livro didático. A metodologia aplicada nas salas de aula não tem colaborado com a construção do conhecimento geográfico em Climatologia nos educandos [...]. Pois a metodologia pragmática ainda percorre na educação, onde o educador aplica a memorizaçáo como base para a formação dos estudantes. Por meio disto, o raciocínio climatológico geográfico vem deixando lacunas no processo de ensino-aprendizagem (SILVA; SILVA, 2014, p. 2).

Felizmente, tem aumentado, mesmo que ainda de forma tímida se comparada à outras áreas da Climatologia brasileira, o número de pesquisas com propostas de práticas de ensino em Climatologia Geográfica que sejam inovadoras e que deixem de lado a tão incômoda memorização de conteúdos. Nesse sentido, a utilização de recursos multimídia tais como, aulas interativas, animaçóes, vídeos e etc. têm ganhado espaço nas salas de aula. Steinke (2014) ressalta que, no estudo de aspectos relacionados ao clima e ao tempo, o papel que o professor desempenha em suas aulas, assim como os recursos utilizados, são de suma importância, uma vez que o conteúdo referente a esses assuntos é demasiado abstrato, mesmo para aqueles alunos com grau de cognição mais elevado. Por isso, justifica-se a utilização de recursos capazes de trazer para a sala de aula estratégias de ensino mais dinâmicas, levando o aluno a participar como agente ativo no processo de ensino-aprendizagem.

$\mathrm{Na}$ Era da Informação, a comunicação vem sendo atrelada ao uso do computador - um de seus símbolos - e a Internet, em um dos meios tecnológicos mais importantes e revolucionários deste período histórico, proporcionando transformações em praticamente todas as dimensões da vida humana. Sobre isso Zambrana e Blanco (1998) afirmam:

Desde a última década do século XX até a presente época, o computador se constituiu em um instrumento chave das chamadas Novas Tecnologias da Informação e Comunicação (NTIC). Ao consolidar-se como um atrativo recurso multimídia de informação e comunicação, o computador propiciou condiçóes favoráveis ao desenvolvimento da educação, fato que já vinha sendo trabalhado desde os anos sessenta quando a informática começou a elaborar programas que facilitassem a aprendizagem de quaisquer conjuntos de saberes (ZAMBRANA e BLANCO, 1998, p. 107).

Sendo assim, a tecnologia pode ser considerada como facilitadora da aprendizagem, principalmente no que concerne aos assuntos mais abstratos, como é o caso dos temas de Climatologia. Fagundes et al. (2015) ressaltam que inúmeras pesquisas têm evidenciado que a compreensão e aprendizagem efetiva de fenômenos abstratos necessita da utilização de objetos de visualização, ou seja, recursos visuais. Neste sentido, materiais didáticos como as animaçóes, podem ser introduzidos no processo de ensino-aprendizagem como objetos de visualização para auxiliar a construção do conhecimento e 
facilitar a aprendizagem dos conteúdos. Heckler et al. (2007), por exemplo, elaboraram e avaliaram um material digital sobre o ensino de óptica e afirmaram:

As animaçóes e as simulaçóes são consideradas, por muitos, a solução dos vários
problemas que os professores de Física enfrentam a tentar explicar para seus
alunos fenômenos demasiado abstratos para serem visualizados através de uma
descriçáo em palavras e demasiados complicados para serem representados através
de uma única figura. Elas possibilitam observar em alguns minutos a evoluçáo
temporal de um fenômeno que levaria horas, dias ou anos em tempo real, além
de permitir ao estudante repetir a observaçáo sempre que desejar (HECKLER et
al, 2007, p. 268).

Nesse contexto, e seguindo as ideias anteriormente apresentadas, o objetivo do presente artigo consiste em apresentar e discutir a aplicabilidade de mais um trabalho multimídia originado do Projeto Climatologia Fácil, desenvolvido pelas equipes dos Laboratórios de Climatologia Geográfica (LCGea) e de Geoiconografia e Multimídias (Lagim) da Universidade de Brasília (UnB). Trata-se de um software para animação de fenômenos de escala sinótica (centros de ação, linhas de instabilidades, sistemas frontais, etc), representados graficamente nas cartas sinóticas, que ocorrem no território brasileiro, com base nas cartas sinóticas disponibilizadas gratuitamente pela Marinha do Brasil. A finalidade do software é servir como recurso didático-pedagógico auxiliar para professores e alunos no estudo da dinâmica das massas de ar e dos sistemas atmosféricos atuantes no Brasil. Além disso descreve-se uma proposta didática, realizada com alunos do curso de graduação em Geografia da UnB, com a utilização do software.

\section{CARTAS SINÓTICAS}

O termo carta sinótica designa um mapa que apresenta alguns elementos que caracterizam o estado do tempo, em uma determinada região e momento. Segundo Garbin et al. (2011), a primeira carta sinótica foi elaborada em torno do ano de 1820. A partir de então, passou por diversas modificaçôes e aprimoramentos até a definição do modelo internacionalmente aceito.

O técnico que elabora as previsões do tempo obtém muitas informaçóes meteorológicas do sistema de comunicaçôes. Essas informações, segundo Forsdyke (1981) são organizadas em um mapa de contornos conhecido como carta sinótica, ou carta do tempo. Nessa carta é possível observar o estado da atmosfera em um determinado momento e a uma determinada altitude. As estações meteorológicas (e seus dados registrados) são plotadas no mapa e representadas por pequenos círculos. O relatório de cada estação é traçado dentro e em volta desse círculo. Os números e símbolos que aparecerem nesse relatório correspondem aos dados meteorológicos referentes aos elementos do clima.

Um desses elementos é a pressão atmosférica. Constitui o elemento fundamental do clima e o mais importante no estudo e pesquisa das condiçóes físicas da atmosfera. Esse elemento é o único que permite a análise direta dessas condiçóes e leva à previsão da evolução das mesmas. Uma vez identificados os valores de 
pressões atmosféricas iguais, esses valores são reduzidos às condições padrão, ou seja, ao nível do mar (excluindo-se, assim, os efeitos da altitude) e plotados em uma carta. Unindo-se os pontos de igual pressão atmosférica, são desenhadas linhas, que delimitam as isóbaras. Por convenção, as isóbaras são traçadas a cada 2, 3 ou 4 milibares $(\mathrm{mb})$ ou hectopascal $(\mathrm{hPa})$ e nos seguintes horários padrão de observação: $00 \mathrm{hZ}, 06 \mathrm{hZ}, 12 \mathrm{hZ}$ e $18 \mathrm{hZ}$ (MIGUENS, 2000). A letra Z corresponde à hora Zulu ou horário de Greenwich. Esse horário é sempre utilizado, não importando a hora local. Trata-se de uma padronização que facilita a interpretação por parte da comunidade científica, em qualquer parte do mundo.

As variações horizontais da pressão atmosférica revelam, na análise da carta, os sistemas de pressáo ou centros de pressão que compóem, no todo, o campo barométrico. Esses sistemas, ou centros, são diferentes entre si, porque apresentam valores diferentes de pressóes. Assim, o desenho do campo barométrico revelará a existência de regióes de alta (anticiclones) e baixa pressão (ciclones), em torno dos quais circulam os ventos. Uma vez determinado gradiente barométrico, é possível indicar a força do vento em determinado lugar. Ainda é possível a identificação de frentes, linhas de instabilidade, zonas de convergência, etc. (MENDONÇA E DANNI-OLIVEIRA, 2007).

As cartas sinóticas são bastante utilizadas em diversos tipos de estudos climáticos. No caso da Geografia, além de outras utilidades, essas cartas servem como suporte à análise rítmica, técnica proposta por Monteiro (1971) que tem por objetivo individualizar os tipos de tempo e acompanhar seu ritmo diariamente. Segundo Borsato e Souza Filho (2008), por meio da análise rítmica é possível caracterizar o tempo atmosférico por meio da dinâmica da circulação atmosférica regional. A caracterização da circulação regional é realizada por meio da análise diária das cartas sinóticas e das imagens de satélite.

Ogashawara (2012) utilizou cartas sinóticas e imagens de satélite para definir os tipos de tempo, em Sáo Paulo, no ano de 2009, e mostrar aplicabilidade da técnica de análise rítmica para estudos ambientais. $\mathrm{O}$ autor reiterou que a utilização das cartas sinóticas é indispensável para a classificação dos tipos de tempo, e que as mesmas fornecem, ao intérprete, um dado empírico para o entendimento da dinâmica atmosférica local.

No caso do ensino, a utilização de cartas sinóticas para a compreensão do mecanismo de produção dos tipos de tempo, há muito já é destacada como sendo um excelente recurso didático. Monteiro (1963), ainda quando lecionava, na década de 1960, se preocupava com os problemas de ordem metodológica no tratamento geográfico do clima. Em suas discussóes, levantou a possibilidade da utilizaçáo de cartas do tempo, coletadas em jornais de boa qualidade, para o ensino e compreensão do clima e do seu ritmo habitual. Segundo o autor, as cartas do tempo fornecem ao professor material altamente útil para trabalhos práticos em um curso de Climatologia:

Desde que se tenha compreendido, através da análise da circulação atmosférica secundária, o ritmo habitual da sucessão anual dos estados atmosféricos, a análise das cartas do tempo pode representar, para o geógrafo um grande instrumento de compreensão. (MONTEIRO, 1963, p. 173) 
No caso de Monteiro (1963), a prática foi aplicada para alunos do ensino superior. Para esse nível de ensino, o professor pode justificar o trabalho da leitura e análise das cartas sinóticas como sendo, entre outras finalidades, indispensável à análise rítmica. Ocorre que, na maioria das disciplinas de Climatologia, no que concerne aos cursos de graduação, os conteúdos programáticos são caracterizados pela descrição dos fenômenos atmosféricos, pelo significado dos elementos do clima e pelo estabelecimento de leis que regem a circulação geral da atmosfera. Sant'Anna Neto (2002), já apontava esse aspecto do ensino da Climatologia, nos cursos de graduaçáo, afirmando que aos alunos são levadas noções fundamentais da Climatologia, porém, desconectadas da realidade social e territorial. Acrescenta-se que, por meio da análise rítmica, é possível incluir a compreensão da dinâmica social e territorial, uma vez que, a esse tipo de análise é possível incorporar um fato geográfico, que se organiza e se distribui em um espaço determinado.

Quando no programa de conhecimentos que o aluno tomará contato, em uma disciplina de Climatologia, está incorporada a análise rítmica, muitas vezes pressupóese que os alunos possuem algum conhecimento prévio sobre análise de cartas sinóticas. Em outros casos, é necessário que o professor ofereça algum treinamento para a leitura e interpretação das cartas sinóticas.

Geralmente, são utilizadas, como instrumento de ensino, as cartas sinóticas de pressão atmosférica na superfície elaboradas pelo Serviço Meteorológico Marinho, órgão do Ministério Marinha do Brasil e disponibilizadas, em seu sítio na internet. ${ }^{1}$ Embora a parte mais detalhada corresponda ao litoral da América do Sul, é possível retirar, dessas cartas, informaçôes referentes aos sistemas atmosféricos atuantes no Brasil. Também podem ser utilizadas as cartas sinóticas de superfície elaboradas pelo Grupo de Previsão de Tempo (GPT) do CPTEC/INPE. Coloridas e com mais recursos visuais, estas cartas apresentam informaçóes para toda América do Sul, porém, sua leitura demanda uma maior prática por parte dos alunos.

De qualquer forma, para um exercício de treinamento de análise de cartas sinóticas, de um período de tempo de poucos dias, pode-se lançar máo da estratégia de fazer uma impressão das cartas diárias (ou mesmo de mais horários sinóticos) e dispô-las, uma ao lado da outra, formando um mosaico, para que se possa aprender a identificar, mesmo que de forma estática, o deslocamento e a evolução dos sistemas atmosféricos atuantes durante aquele período, como mostrado na figura 1 - um mosaico de cartas sinóticas, pelas quais é possível acompanhar, durante seis dias, a evolução dos sistemas frontais que atuaram, no Brasil, entre 21 a 26 de março de 2016.

Disponível em: <http://www.mar.mil.br/> 
Figura 1 - Mosaico de cartas sinóticas da Marinha do Brasil, elaboradas às $00 \mathrm{hZ}$ Hora Universal (21 horas no horário de Brasília), mostrando o desenvolvimento dos sistemas frontais atuantes no Brasil no período de 21/03/2016 a 26/03/2016

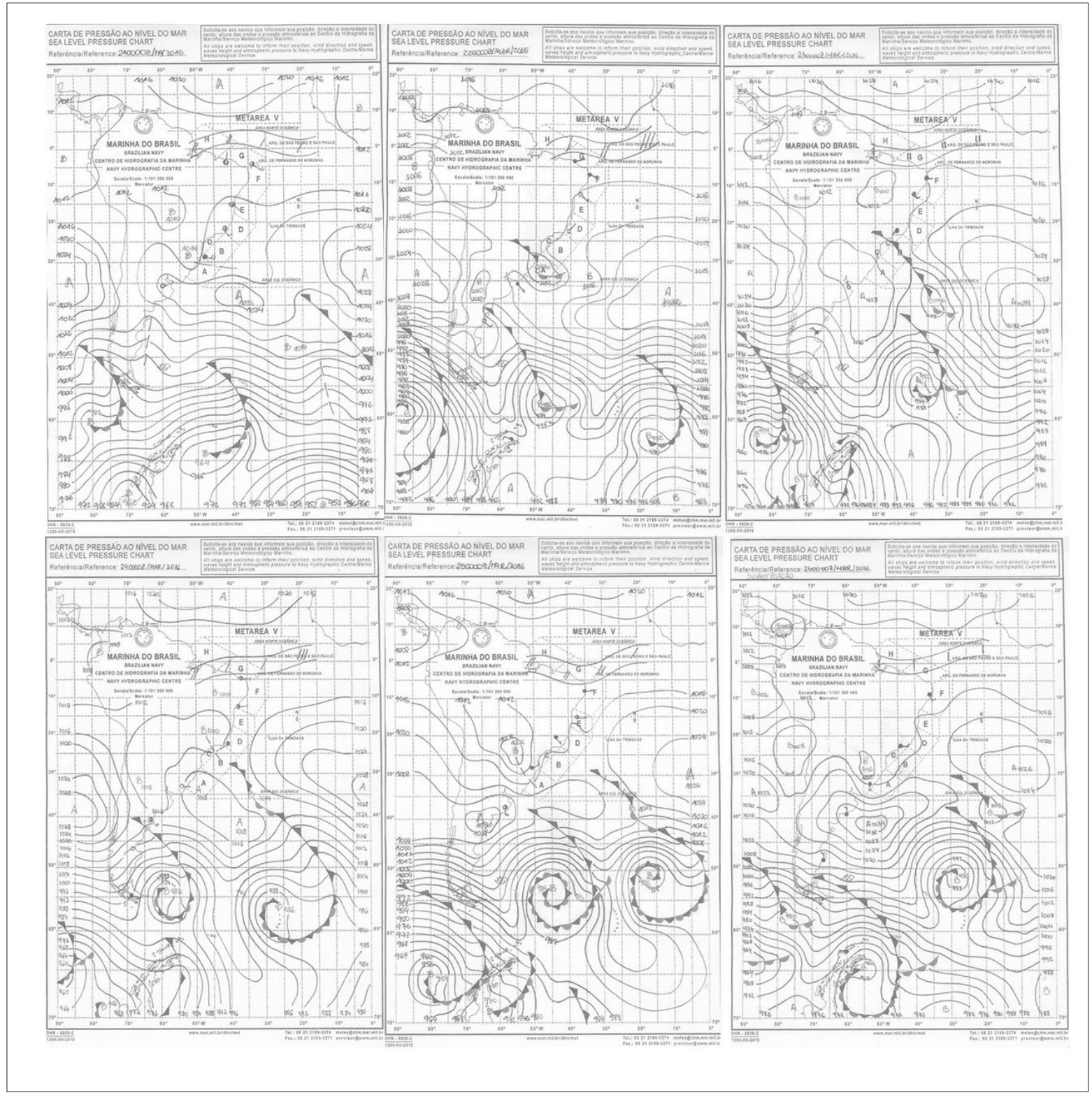

Fonte: Marinha do Brasil. Serviço Meteorológico Brasileiro. Disponível em:<https://www.mar.mil.br/dhn/chm/ meteo/prev/cartas/cartas.htm>.

Indicações de como devem ser realizadas análises de cartas sinóticas podem ser encontradas em Nimer (1989). O autor aponta, como exemplo, algumas situaçóes de tempo, no Brasil, que são representativos das frequências observadas de alguns elementos (massas de ar, sistemas frontais, ciclones e anticiclones) para as quatro estaçóes do ano. Já no material elaborado pela FUNBEC (1980) é possível observar algumas indicaçóes de como analisar cartas sinóticas para o reconhecimento dos centros de pressão e dos sistemas atmosféricos atuantes em um determinado local. De forma geral, deve-se 
observar a carta como um todo para identificar as posiçôes dos centros de alta (A) e baixa (B) pressão, dos sistemas frontais e da zona de convergência. Também é necessário observar o valor da pressão nos núcleos dos sistemas de alta (A) e baixa (B) pressão e suas alteraçôes ao longo do período estudado. A partir dessas variaçôes é possível, por exemplo, comparar a pressão de seus núcleos revelando, por meio da diferença da pressão, qual sistema apresentará mais energia para o deslocamento.

Porém, em alguns casos, quando o período estudado compreender muitos dias, a utilização de cartas sinóticas impressas pode se tornar inviável. Para resolver essa questáo, elaborou-se uma proposta didática que se refere à utilização de uma página na internet para a apresentação de animação de fenômenos de escala sinótica (centros de ação, linhas de instabilidades, sistemas frontais, etc.) para que o aluno possa observar, em pequeno espaço de tempo, os deslocamentos dos centros de pressão, compreendidos no seu sentido mais amplo, abrangendo ainda os sistemas frontais e demais fenômenos dinâmicos que duram horas, dias, meses e etc. Com essa proposta, acredita-se que a identificação da dinâmica dos fenômenos, nas cartas sinóticas, fique mais clara, já que o dinamismo que os reveste pode ser representado com a animação.

\section{DESENVOLVIMENTO DO SOFTWARE DE ANIMAÇÃO}

A ideia de tentar desenvolver uma forma de animar os fenômenos representados nas cartas sinóticas surgiu durante as aulas da disciplina optativa Análise de Microclimas (disciplina da grade curricular do curso de graduaçáo em Geografia da UnB), cujo programa tem por objetivo principal capacitar os alunos a utilizarem a técnica de análise rítmica preconizada por Monteiro (1971). Segundo Zavattini (2005), para realizar a análise rítmica, além da elaboração de um gráfico, contendo as informações diárias dos parâmetros meteorológicos, deve-se identificar os estados atmosféricos por meio das cartas sinóticas.

Até o primeiro semestre de 2016, para o ensino da análise das cartas sinóticas, na referida disciplina, eram utilizados os desenhos de cartas, do período de 16 a 30 de abril de 1971 (quinze dias), presentes no material didático, em formato de livro, elaborado pela FUNBEC (1981). Os desenhos, chamados de mapas do tempo, foram baseados em cartas sinóticas oficiais. Esse material didático, intitulado "O Tempo e o Clima”, foi destinado aos alunos dos ensinos médio e superior, para o estudo a respeito de noções básicas da dinâmica atmosférica. Embora careça de atualização, esse material constitui-se um excelente apoio para o professor e ainda pode ser utilizado, desde que com a devida mediação.

A figura 2 mostra um exemplo desses mapas do tempo, que correspondem aos dias 24,25 e 26 de abril de 1971. De posse do conjunto total de mapas do tempo, aos alunos, foi proposta uma atividade na qual eles deveriam analisar o deslocamento de uma extensa frente fria durante esses três dias. Os alunos deveriam chegar à conclusão: dia 24, a frente fria estendia-se pelo interior do Brasil desde o Amazonas até o sul da Bahia e deslocou-se rapidamente devido à grande atividade da massa polar, que dominou mais 
da metade do Brasil; dia 25, a frente encontrava-se estacionária no litoral do Nordeste, afastou-se do continente e deslocou-se em direção ao oceano; dia 26, a frente fria, já em dissipação, estendia-se pelo interior do Brasil atuando sobre Manaus e definiu-se como fria ao norte de Salvador.

Figura 2 - Mapas do tempo dos dias 24 (A), 25 (B) e 26 (C) de abril de 1971, mostrando o deslocamento da frente fria

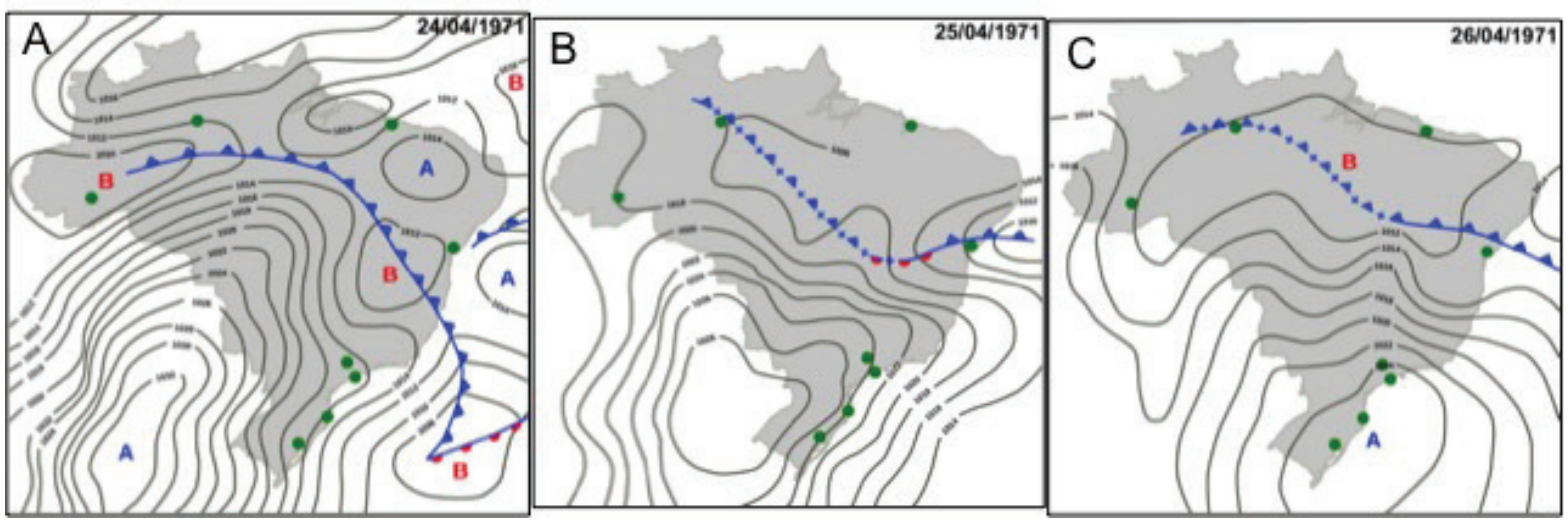

Fonte: FUNBEC, 1981, adaptado pelos autores

Observou-se que os alunos não apresentaram dificuldades em identificar o deslocamento da frente fria e nem a evolução temporal do sistema de alta pressão utilizando três figuras estáticas. Contudo, o material da FUNBEC propóe que sejam analisados quinze dias (16 a 31 de abril de 1971), o que demanda o manuseio, em sala de aula, de muitas figuras impressas em folhas de papel. Os alunos nem sequer possuíam mesas adequadas para dispor tantas folhas, lado a lado. Assim, muito tempo da aula era demandado somente para que os alunos conseguissem organizar as figuras com os mapas do tempo.

Uma forma de melhorar a visualização da evolução dos fenômenos foi solicitar aos alunos que pintassem os intervalos entre as isóbaras, porém, esse fato revelou-se ainda mais dispendioso com relação ao tempo da aula.

Resolveu-se, então, digitalizar os desenhos dos mapas do tempo, atribuir-lhes cores e produzir um GIF animado (Graphics Interchange Format ou formato de intercâmbio de gráficos). O GIF animado nada mais é do que um GIF composto de várias imagens do formato GIF, compactadas em um só arquivo, que podem ser animadas. No caso, os quinze desenhos referentes aos mapas do tempo foram compactados em um só arquivo. Essa pequena animação passou a ser utilizada, na aula, ao invés das folhas de papel.

A resposta dos alunos em relação à essa troca de recurso foi bastante positiva. Os alunos se tornaram mais atuantes na aula e afirmaram que a pequena animação facilitou a identificação do deslocamento dos sistemas atmosféricos quando comparada às figuras estáticas. Os alunos perceberam que o objetivo da atividade era observar a evoluçáo temporal e espacial dos sistemas atmosféricos. 
A partir dessa experiência positiva, e baseados em resultados de outras pesquisas que compararam a utilização de animaçóes e de imagens estáticas para o ensino de assuntos específicos, tal como Oliveira (2012), as equipes dos Laboratório de Climatologia Geográfica (LCGea) e Laboratório de Geoiconografia e Multimídias -Lagim, da UnB desenvolveram um software intitulado "Animação de Cartas Sinóticas". No presente momento o software está sendo atualizado, porém, será disponibilizado, gratuitamente, aos estudantes e professores por meio do futuro site do Lagim. ${ }^{2}$

No planejamento da navegação do software definiu-se os itens importantes do menu de navegação: A Página Inicial contém informações dos laboratórios e dos idealizadores; $\mathrm{Na}$ Apresentação, o usuário obtém informações a respeito do objetivo do software; No item Contato, disponibiliza-se os e-mails do LCGea e do Lagim; O item Decifrando a Carta Sinótica traz uma explicação do que vem a ser uma carta sinótica e dicas de como analisá-la. No item Animação, o usuário pode escolher o período das cartas que gostaria de animar (período inicial e final) e período de exibição da sequência de imagens (velocidade de exibição). Até o presente momento estão disponíveis, para animação, cartas sinóticas desde o ano de 2015. Futuramente estarão disponíveis para animação todas as cartas sinóticas contidas na página da Marinha do Brasil.

Executou-se a organização do software em linguagem html (Hipertext Markup Language). Para realização da animação das cartas foram escritos códigos em linguagem Javascript. Basicamente o efeito da animação é realizado da seguinte forma: dispóe-se de uma determinada sequência temporal de imagens das cartas sinóticas, em formato JPEG (Joint Photographic Experts Group), obtidas no endereço eletrônico do Serviço Meteorológico Marinho. Em essência, a cada período pré-determinado de tempo (por exemplo, a cada quinhentos milissegundos) exibe-se, iterativamente, uma imagem em seguida da outra, em ordem crescente de sua data de elaboração, no recurso tag/img da linguagem html. Assim, tem-se a impressão de "movimento" das cartas sinóticas. Na figura 3 é mostrada a página na qual é possível escolher o período da animação.

Disponível em: <www.lagim.unb.br>. 
Figura 3 - Página da animação do software - Animação de Cartas Sinóticas

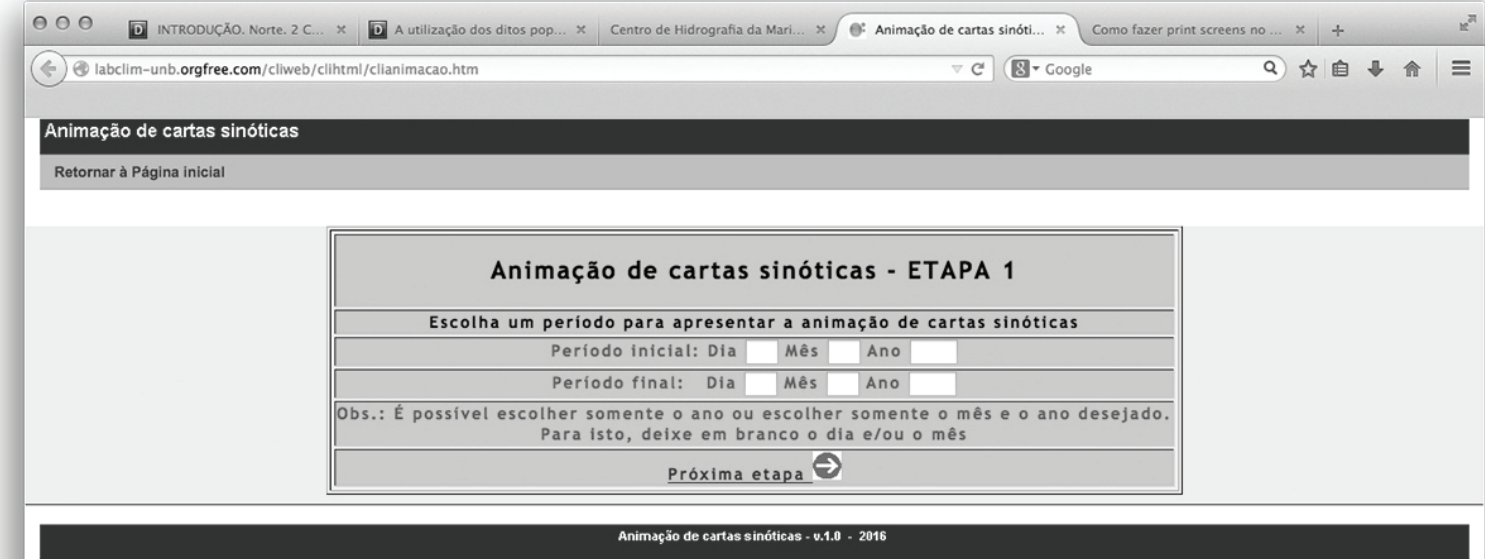

Fonte: Labclim. Disponível em: <http://labclim-unb.orgfree.com/cliweb/clihtml/clianimacao.htm>

\section{PRÁTICA DIDÁTICA UTILIZANDO A ANIMAÇÃO}

A prática didática descrita a seguir foi aplicada aos alunos da disciplina Análise de Microclimas, no segundo semestre de 2016, do curso de graduação em Geografia da UnB. A prática tinha por objetivo identificar e descrever os sistemas atmosféricos que atuaram no Brasil, durante os dias 01 a 30 de agosto de 2016, por meio do software Animação de Cartas Sinóticas. Ressalta-se que os alunos já tinham conhecimento sobre noçóes básicas de Meteorologia dinâmica.

Os alunos receberam cópias impressas das cartas sinóticas da Marinha, dos trinta dias estudados e dispunham de dados meteorológicos diários obtidos junto ao banco de dados meteorológico (BDMEP) do Instituto Nacional de Meteorologia (INMET) para auxiliar suas análises.

A atividade tinha como objetivo analisar a sequência de cartas sinóticas dos trinta dias de agosto. Para delimitar melhor a área estudada foram escolhidas duas cidades, em diferentes regiôes do Brasil: Brasília e Porto Alegre. Para cada uma dessas cidades foram elaborados gráficos de temperatura do ar (linear), pressão atmosférica (linear), umidade relativa (linear) e precipitação (barras) para os dias do período considerado. Para cada dia, foram identificados os centros de ação (e suas respectivas massas de ar) responsáveis pelos tipos de tempo naquelas cidades e as frentes associadas.

A sequência em questão mostra uma evolução do tempo no inverno, no Brasil. O ıticiclone do Atlântico Sul predomina sobre 
o centro do país, enquanto que, no sul, as invasões do anticiclone Polar são constantes. Em agosto de 2016, segundo CPTEC (2016), as chuvas foram mais acentuadas nas regióes sul, centro-oeste e sul da Região Sudeste no decorrer da segunda quinzena de agosto, o que não corresponde ao ritmo habitual. Neste período, a atividade frontal também foi favorecida, com ocorrência de chuvas acima da média histórica entre o centro-norte da Região Sul e o centro-sul das Regióes Sudeste e Centro-Oeste. Neste mesmo período, incursóes da massa polar Atlântica resultaram na ocorrência de geada em vários municípios no centro-sul do Brasil.

Na primeira quinzena do mês de agosto de 2016, grande parte do Brasil encontravase sob o domínio do anticiclone do Atlântico Sul, o que produziu um tempo quente e seco. Já na segunda quinzena, houve o deslocamento de três frentes frias vigorosas do sul para o Sudeste. A maior parte da chuva ficou restrita à Região Sul, porém, estas frentes frias levaram chuva ao Centro-Oeste, ao Espírito Santo, Sáo Paulo, Rio de Janeiro e ao Norte de Minas Gerais. O Nordeste, e grande parte do norte, continuaram secos na segunda quinzena de agosto. Em Brasília foi registrada chuva entre os dias 13 e 24 de agosto, o que fez com que a média histórica do mês fosse superada. Já a cidade de Porto Alegre foi atingida por três ondas de frio e a chuva registrada também ficou acima da média histórica para o mês.

Após a apresentação do software, os alunos tiveram a oportunidade de assistir à animação das cartas sinóticas em diversas velocidades, até a escolha da velocidade adequada para que os mesmos pudessem identificar os sistemas meteorológicos. A animação foi apresentada inúmeras vezes e, com a intermediação do professor, esse novo elemento (animaçáo) foi visto com um novo olhar pelos alunos. Observou-se um interesse maior pelo assunto estudado, talvez porque a linguagem multimídia, como a animaçáo, seja vista pelos alunos como um descanso e não como aula, como afirma Moran (1995), o que modifica a sua postura em relação ao conteúdo ministrado.

Em seguida, uma série de questóes foi proposta para os alunos sobre o comportamento dos sistemas meteorológicos e suas repercussóes nas duas cidades estudadas, no mês de agosto. Solicitou-se que os alunos verificassem quais as massas de ar que mais atuaram nas duas cidades, registrando os dias em que ocorreram chuvas, verificando a relação entre a ocorrência de chuva com as passagens das frentes frias e as alteraçóes no tempo decorrentes dessas passagens, avaliando a alteração nos parâmetros meteorológicos.

A atividade foi encerrada com a elaboração de um pequeno relatório de aula prática, no qual os alunos descreveram a atividade em si e suas impressóes sobre a utilização do recurso animação.

\section{CONSIDERAÇÓES FINAIS}

Para que a prática didática pudesse atingir os objetivos propostos, os alunos deveriam repetir a animação mais de uma vez, antes e depois das questóes, durante a aula e em casa. Para que isso pudesse ocorrer, a animação ficou disponibilizada na Internet, em um 
sítio de conhecimento do aluno. Ao avaliar a atividade, observou-se que a linguagem multimídia demanda estratégias pedagógicas diferenciadas daquelas que tradicionalmente são utilizadas, orientadas pelas linguagens verbal e escrita. A prática didática proposta fez com que os alunos se mantivessem interessados, participativos e questionadores durante as aulas. Sendo assim, acredita-se que a prática interferiu de forma positiva no aprendizado, funcionando como um recurso facilitador na compreensão do ritmo da sucessão anual dos estados atmosféricos.

Vale ressaltar que o software não foi elaborado somente para a utilizaçáo no ensino superior, pelo contrário, é desejo dos autores que o professor do ensino básico também utilize o software em suas aulas. Apesar de a leitura de uma carta sinótica requerer um certo grau de conhecimento de meteorologia dinâmica, é possível a sua utilizaçáo para, por exemplo, o ensino de frente fria e seus deslocamentos por sobre o Brasil. Inúmeras práticas didáticas podem ser elaboradas com a utilização do software, para que a memorização de conceitos dê lugar à compreensão de fenômenos e a aprendizagem se torne significativa. 


\section{REFERÊNCIAS BIBLIOGRÁFICAS}

BORSATO, V. A.; SOUZA-FILHO, E. E. O ritmo climático e episódios pluviométricos no ano de 1980 na vertente ocidental da Bacia do Alto Rio Paraná Brasil. Geografia,Londrina. v. 17, pp. 83-109, 2008.

BRITO, M. C. de; FERREIRA, C. de C. M. Por uma Climatologia Geográfica escolar no cotidiano: estimulando reflexões e a criatividade dos educandos. Geonorte, Edição Especial, Manaus, v.1, n.5, pp. 218-231, 2012.

COSTELLA, R. Z. A importância dos desafios na construção do conhecimento geográfico. In: REGO, N; CASTROGIOVANNI, A. C; KAERCHER. Geografia: práticas pedagógicas para o ensino médio. Porto Alegre: Artmed, 2007. pp. 49-54.

FAGUNDES, A. L.; SILVA, T. da; BARROSO, M. F. Aprendizagem mediada por uma hipermídia educacional. Revista Latino-Americana de Educação em Astronomia, São Carlos,n. 20, pp. 91-114, 2015.

FIALHO, E. S. Climatologia: ensino e emprego de geotecnologias. Revista Brasileira de Climatologia,Curitiba, v. 13, pp. 30-50, 2013.

FORSDYKE, A. G. Previsão do tempo e clima. São Paulo: Melhoramentos, 1981.

FUNBEC. Fundação Brasileira para o Desenvolvimento do Ensino de Ciências. Projeto brasileiro para o ensino de Geografia: o tempo e o clima São Paulo: Edart, 1980. (Guia do professor)

GARBIN, E. P.; SANTIL, F. L. de P.; SILVEIRA, H. Análise da percepção das variáveis de acordo com a categorização das feiçóes das cartas sinóticas. Revista Brasileira de Cartografia. Rio de Janeiro,n. 63/03, pp. 427-438, 2011.

HECKLER, V.; SARAIVA, M de F. O.; OLIVEIRA FILHO, K. de S. Uso de simuladores, imagens e simulaçóes como ferramentas auxiliares no ensino/aprendizagem de óptica. Revista Brasileira de Ensino de Física, São Paulo, v. 29, n. 2, pp.267-273, 2007. MCTIC/INPE/CPTEC. Infoclima, ano 23, n. 9, set. 2016. Disponível em:<http://infoclima.cptec.inpe.br/ rinfo/pdf_infoclima/201609.pdf>. Acesso em: out. 2016.

MENDONÇA, F.; DANNI-OLIVEIRA, I. M. Climatologia: noçóes básicas e climas do Brasil. São Paulo: Oficina de Textos, 2007.

MIGUENS, A. P. A Ciência e a arte.V. III :navegação eletrônica em condiçóes especiais. Rio de Janeiro: Diretoria de Hidrografia e Negação da Marinha do Brasil/ UERJ, 2000. Disponível em:<https://www.mar.mil.br/dhn/bhmn/download/cap-45.pdf>. Acesso em: jan. 2016.

MONTEIRO, C. A. de F. Sobre a Análise Geográfica de Sequências de Cartas de Tempo: pequeno ensaio metodológico sobre o estudo do clima no escopo da Geografia. Sáo Paulo. Revista Geográfica, t. 32, n. 58, pp. 169-179, 1963.

- Análise rítmica em Climatologia: problemas da atualidade climática em Sáo Paulo e achegas para um programa de trabalho. Climatologia. São Paulo. n. 1, pp. 1-21, 1971. 
MORAN, J. M. O vídeo na sala de aula. Revista Comunicação \& Educação. São Paulo, ECA. n. 2, pp. 27-35, jan.-abr, 1995.

NIMER, E. Climatologia do Brasil. 2. ed. Rio de Janeiro: IBGE, 1989.

OGASHAWARA, I. Análise rítmica e a Climatologia Geográfica brasileira. Revista Eletrônica Geoaraguaia. Barra do Garças (MT). v. 2, n.2, pp. 57-72, 2012. Disponível em:<http://revistas.cua.ufmt.br/geoaraguaia/index.php/geo/article/view/22/22>. Acesso em: julho de 2016.

OLIVEIRA, I. J. A. A Cartografia na formação do professor de Geografia: análise da rede pública municipal de Goiânia. In: MORAIS, E. M. B; MORAES, L. B. (Orgs.).Formação de professores: conteúdos e metodologias de ensino de Geografia. Goiânia: NEPEG, 2010, pp. 123-136.

OLIVEIRA, T. de L. Estudo comparativo entre materiais didáticos estáticos e dinâmicos voltados ao ensino-aprendizagem de mecanismos de reações químicas orgânicas: uma abordagem do design instrucional. 2012. 137 f. Dissertação (Mestrado em Design). Departamento de Design, Universidade Federal do Paraná, Curitiba, 2012.

SANT'ANNA NETO, J. L. Análise geográfica do clima: produção de conhecimento e consideraçóes sobre o ensino. Geografia. Londrina, v. 11, n. 2, pp. 321-328. jul./dez, 2002.

SANTOS,T. O. dos; ROCHA V. M. A instrumentação meteorológica como recurso didático-pedagógico aplicada ao conteúdo de Climatologia nas aulas de Geografia do ensino fundamental. In: SIMPÓSIO BRASILEIROS DE CLIMATOLOGIA GEOGRÁFICA, 10. 2014, Curitiba. Anais... Curitiba: 2014. pp. $1724-1731$.

SILVA, L. F. P. da. A Utilização de Jogos, Animações e Simuladores Computadorizados como uma Nova Estratégia Didática na Construção do Conhecimento. In: ENCONTRO DE FORMAÇÃO DE PROFESSORES, 4., Tiradentes, 2011. Tiradentes, MG. Anais... Tiradentes: 2011.pp.1-15. Disponível em:<https://www.unit.br/hotsites/2011/enc_formacao_professores/arquivos/artigos/GT_1_ESPACOS_EDUCATIVOS/A_UTILIZACAO_ JOGOS_ANIMACOES_SIMULADORES_COMPUTADORIZADOS_NOVA_ ESTRATEGIA_DIDATICA_CONSTRUCAO_CONHECIMENTO.PDF>. Acesso em: jun. 2016.

SILVA, M. C. A. da; SILVA, F. G. F de A. As Noções de Climatologia na Construção do Conhecimento da Ciência Geográfica no Ensino Médio: Estudo de Caso da Escola de Referência Simon Bolívar no Município de Jaboatão Dos Guararapes-PE. In: CONGRESSO BRASILEIRO DE GEÓGRAFOS, 7. 2014, Vitória, Anais... Vitória, 2014. pp. 1-12.

STEINKE, E. T. Climatologia Fácil. São Paulo: Oficina de Textos, 2012.

Utilização da multimídia no Ensino Fundamental como instrumento de ensino de temas em Climatologia. Caminhos da Geografia, Uberlândia, v. 15, n. 51, pp. 127- 137, 2014 .

STEINKE, V. A.; CARVALHO, A. C. A. As dimensões da formação de profissionais em geografia no Brasil: reflexôes introdutórias. In: SILVA, E. I. da; PIRES, L. M. (Orgs.).Desafios da didática de Geografia. Goiânia: EdPUC Goiás, 2013. pp. 69-86. 
TAVEIRA, I. A. P.; STEINKE, E. T. Identificação de temas em Climatologia de difícil transposição didática no Ensino Fundamental. In: CONGRESSO DE INICIAÇÃO CIENTÍFICA DO DF 18.; CONGRESSO DE INICIAÇÃO CIENTÍFICA DA ỦNB, 9. 2014, Brasília. Anais... Brasília: 2014. 1 CD-ROM.

ZAMBRANA, J. J. D; BLANCO, J. J. Tecnologías de la información en la educación. Madrid: Anaya Multimedia, 1998.

ZAVATTINI, J. A. A Razão da Influência: uma teoria do clima. Revista Brasileira de Climatologia. Curitiba, v.1, n.1, pp. 146-158.2005.

Recebido para publicação em Agosto de 2017 Aceito para publicação em Dezembro de 2017 